\title{
Evaluation of Growth, Yield and Energy Requirements of Hydroponic 'Green Oak' Lettuce under Led Light with High Plants Density Condition
}

\author{
Napat Watjanatepin \\ Solar Energy Research and Technology Transfer Center, \\ Rajamangala University of Technology Suvarnabhumi, Nonthaburi, Thailand \\ watjanatepin.n@gmail.com
}

\begin{abstract}
The Hydroponic System (HS) has obtained the soilless technology can produce more than 10 crops of leafy vegetable with rapid growth, high yield and superior quality. The aim of this study is to identify and monitor the hydroponic "Green Oak" lettuce growth development and yield under LED supplement and to evaluate the start-up cost and energy consumption of the hydroponic system with LED light. The NFT-hydroponic and commercial nutrient solution under high plant's density condition and three difference of LED array was applied. Plant yield and energy consumption were evaluated by the method of Poulet and Barbosa. The results show that the hydroponic "Green-Oak" lettuce under LED R70+B30 indicated the highest yield. The start-up cost of HS-LED is about $220 \mathrm{USD} / \mathrm{m}^{2}$. The energy per unit of total biomass is $0.038 \mathrm{kWh} / \mathrm{g}$ and the power density of the proposed LED lighting in average is $0.22 \mathrm{~kW} / \mathrm{m}^{2}$. It is possible to apply LED lighting for hydroponic greenhouse in the high plant's density which could produce a high yield and a good quality of the lettuce. The LED light array consumed the largest number of energy, for energy sustainability, the LED needs to be switched to low power consumption types and a new design for the LED light source should be applied. The results from this study could be applied to design for the effective of HS-LED in the next step.
\end{abstract}

$\underline{\text { Key words: LED light, hydroponic greenhouse, high plant's density, energy consumption, start-up cost, yield }}$

\section{INTRODUCTION}

Climate change is the one of the major causes that affects changes of the world environment. These changes include weather characteristics such as the temperature increase, rain falling during Winter, frequent heavy flooding, rise in the sea level and the decrease of agricultural land by human invade and so on. Meanwhile, the world's population will reach 8 billion in the next 5 years and even up reach to 10 billion in the year 2056 (Anonymus, 2019). Food shortage and food insecurity occurs in some regions of the world such as Africa, Asia and Central America (Anonymous, 2017). Agricultural technologies could be applied to the farmers and these modern agricultural applications could be used to achieve high yield of the plant production.

The hydroponic plantation system has obtained the soilless technology from developed countries and can produce more than 10 crops of leafy vegetable with consistently superior quality, high yield and rapid growth all year-round (Montri and Wattanapreechanon, 2006).
The hydroponic system could produce the high yield, reduce chemical fertilizer and save the water more than conventional plant production.

The 30 years ago, the first hydroponics for plant production program in Thailand has been conducted under the HRH Princess Maha Chakri Sirindhorn at the Royal Chittralada Palace. There were also, many research studies held by Kasetsart University under the tutelage of $\mathrm{FAO}$ to find out the possibility and identify suitable techniques for hydroponic plant production in Thailand (Attanandana and Watcharothayan, 1988; Juthamas and Boonsongsri, 1988; Koohakan et al., 2008). The hydroponic cultivating system in Thailand has expanded to promote over the country as the private sector. Nowadays, Thailand can produce high quality of the hydroponic vegetables and supply the plant production to the high cost market. The Nutrient Film Technique (NFT) is the most popular technique due to an attractive platform. In addition to that it could urge the production cycle especially in green leafy vegetables. Usually, the plant density for the hydroponic cultivation is about

Corresponding Author: Napat Watjanatepin, Solar Energy Research and technology Transfer Center, 
24 plants $/ \mathrm{m}^{2}$ (Donnell et al., 2011) to 43 plants $/ \mathrm{m}^{2}$ (Poulet et al., 2014). If we grow the hydroponic lettuce in the green house with high plant's density which could produce a high yield as a good quality of the lettuce? This is the interesting question for the researcher.

However, the hydroponic vegetables farming in Thailand could be grown within the greenhouse under the natural sunlight under hot and humid climate (Koohakan et al., 2008; Matsumoto, 2002). That cause of negative effect to the plant production under the greenhouse without an environmental control system. In 2014, Mahidol University cooperated with the National Innovation Agency (NIA) and a start-up company "Copack Co., Ltd" to present the first indoor farming project "Grow Laboratory". They are able to produce the green vegetable (such as "Green Oak" lettuce 'Red Oak' lettuce, Cos lettuce and medical plants under soil and soil-less with the LED light and fully controlled environment.

In 2016, the Thai Government announced the "Thailand 4.0 Policy " to be a road map for the development of the country. The plant factory will become one of the new industries that Thailand proposed. The plant factories using the artificial light to produce crops with high quality and efficiency can provide optimal growth condition of the plants without influence from the external environments (Kim et al., 2018).

These concepts motivated the researcher to create a small-sized experimental greenhouse and to study the plant growth and development, plant yield, start-up cost of the system, energy and power consumption of the hydroponics in high plant density under different spectral distribution of the LED light. Inside the greenhouses is control the humidity by fogging spray and control the air-flow by using a ventilating fan. The goals of this study are to identify and monitor the hydroponics 'Green Oak' lettuce growth development and yield under the LED with high plants density condition. Evaluate the start-up cost, power and energy consumption of the provided system. This study could answer the following research questions: "Is it possible to grow hydroponic lettuce within indoor greenhouse with high plants density condition by using the LED lighting?" and "What are the possibilities to reduce the energy and power consumption of such an installation).

\section{MATERIALS AND METHODS}

Plant and nutrient solution: Seed of "Green Oak" lettuce (Metro seed Agricultural Co., Ltd, Thailand) were sown in the wet sponge cubes $(2.5 \times 2.5 \times 2.5 \mathrm{~cm})$ and placed in the plastic tray. Water is added into the tray until the water level reach $1.5 \mathrm{~cm}$ from the bottom. The tray is kept in the black plastic bag for 3 days. The tray is then moved to the low radiation light for another 4 days until the lettuce have 2-4 leaves. The tray is then transferred to the hydroponics bed on day 7 th and finally, the experiments can be performed till the harvest at day 36th (Kim et al., 2018). This study used the commercial nutrient solution concentration in mg/L: N-300; P-75; K-250; Ca-400; Mg-75 S-400; Fe-5; Mn-2; Cu-0.5; Zn-0.5; B-1; Mo-0.001; $\mathrm{Cl}-0.5$ (Thai green, Thailand) at the initial $\mathrm{pH}$ of 5.8 and the Electrical Conductivity (EC) of $1.5 \mathrm{mS} / \mathrm{cm}$. The nutrient solution was renewed every week and the EC is adjusted to $1.2-1.3 \mathrm{mS} / \mathrm{cm}$ with the $\mathrm{pH}$ of $5.8-6.0$ (Chen et al., 2016).

LED lighting: There are 3 sets of custom-made LED array lighting by usingRred (R) LED (640-660 mm) combined with the Blue (B) LED (440-460 mm). LED R70+B30 consist of 63 of R LED and 27 of B LED. The LEDs are bleed type $3 \mathrm{~W}, 8 \mathrm{~mm}$ diameter installed on the square aluminum PCB $(15 \times 10 \mathrm{~cm})$ of $6 \mathrm{LEDs}$ in total. The $200 \mathrm{~W} / 12 \mathrm{~V}$ of the switching power supply was used as a LED driver. The spectrum distribution of the LELD R70+B30 is as show in Fig. 1a.

LED R50+B50 consist of 45 of R LED combined with 45 of $B$ plus 45 of R LED. The installation and LED drives are similar with LED R70+B30. The spectrum distribution of the LED R50+B50 is as show in Fig. $1 \mathrm{~b}$.

The spectrum distribution of LED R $30+B 70$ is as shown in Fig. 1c. LED R30+B70 consist of 27 of R LED plus 63 of B LED and used a LED driver similar to LED $\mathrm{R} 70+\mathrm{B} 30$.

Hydroponics System (HS): The NFT-HS is comprised of six square PVC pipes ( $11 \mathrm{~cm}$ wide, $4.5 \mathrm{~cm}$ high and $400 \mathrm{~cm}$ long) and placed in parallel at $17.5 \mathrm{~cm}$ apart from center to center. The plant's density is this study was estimated to be about 60 plant $/ \mathrm{m}^{2}$ Fig. 2. The distance from head to head is about $10 \mathrm{~cm}$. The hydroponics bed is mounted on a commercial aluminum growth bench at $75 \mathrm{~cm}$ high and $375 \mathrm{~cm}$ long. The nutrient container capacity is $70 \mathrm{~L}$, the volume of nutrient solution is $50 \mathrm{~L}$. The nutrient pump has an output of $2100 \mathrm{l} / \mathrm{h}$ and the power of $38 \mathrm{~W}$. The pump is supplied by AC single phase $220 \mathrm{~V}, 50 \mathrm{~Hz}$ (manufacture data). The tap water with cartridge water filter was used for the water supply Fig. 3 . The fogging pump output is 30 $\mathrm{W}, 1738 \mathrm{l}$, AC power supply $220 \mathrm{~V}, 50 \mathrm{~Hz}$. The fogging pump was used for drive the four of fogging spray. The fogging pump will operate in case the temperature exceeds 

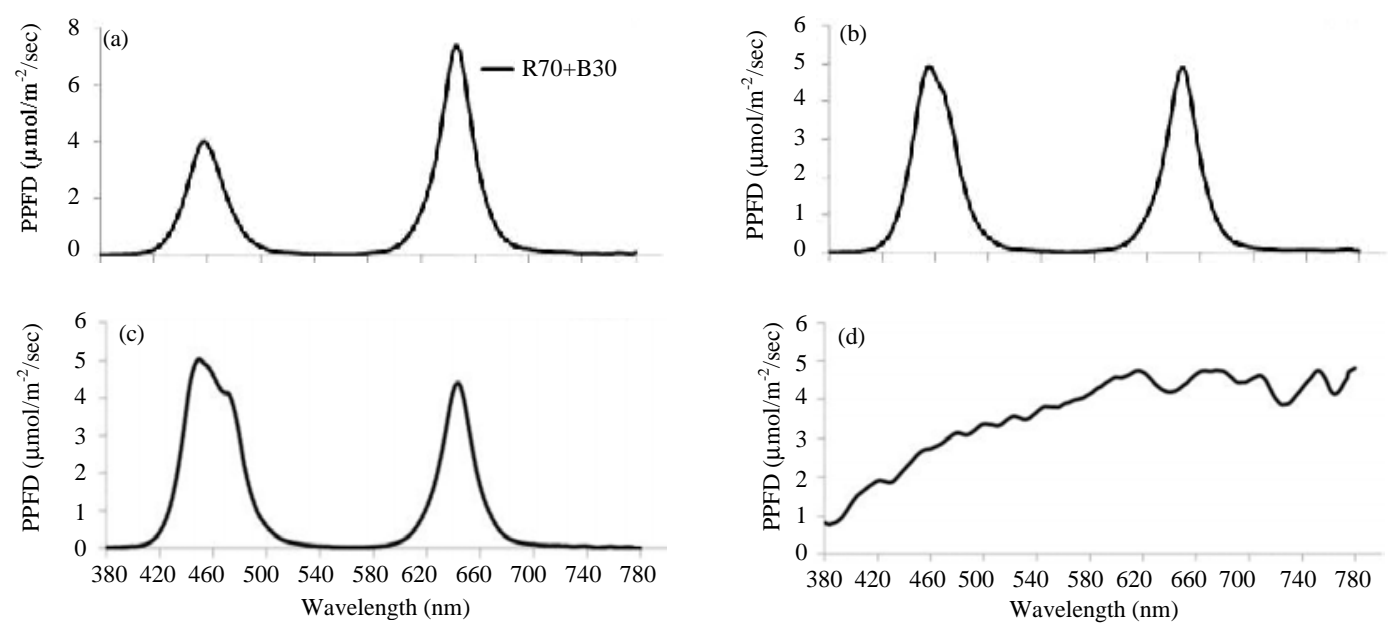

Fig. 1: The spectrum distribution of LED array and Sun at the test site: a) LED array of R70+B30; b) LED of R50+B50; c) LED of R30+B70 and d) Sunlight on 21 March 2018 (11.50 am)

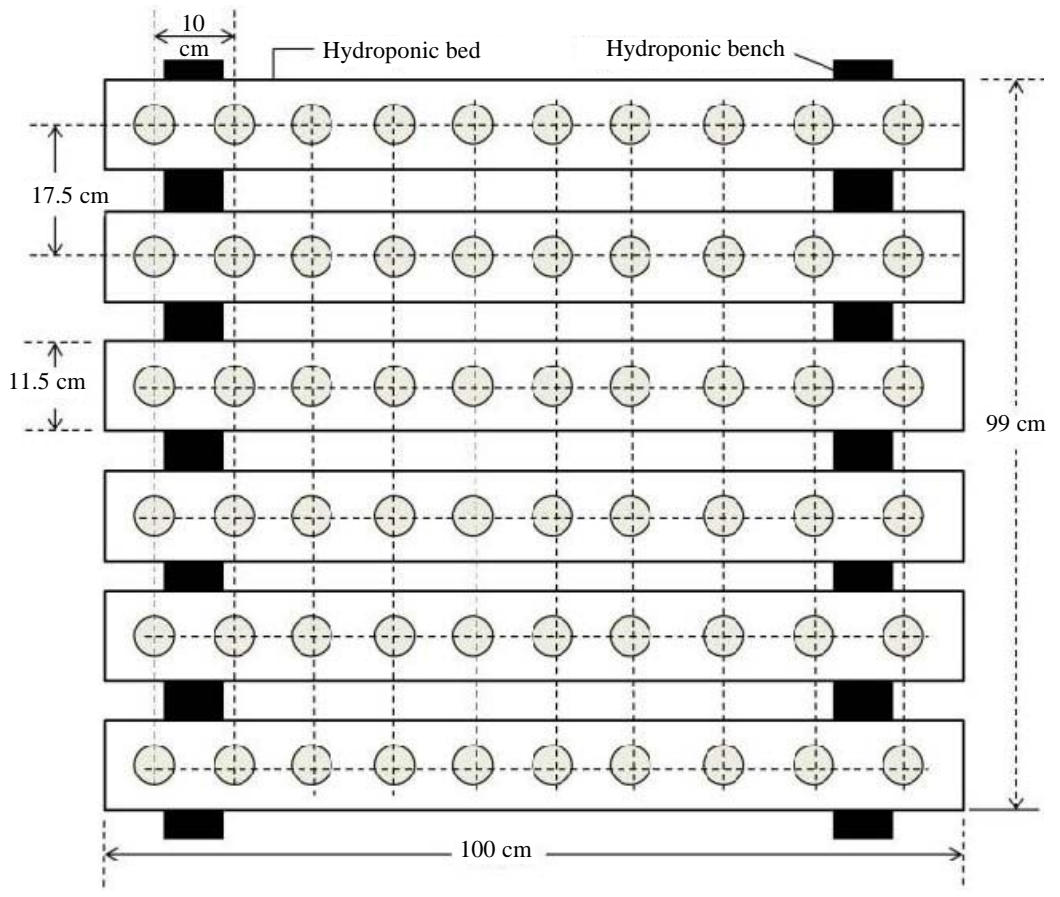

Fig. 2: The hydroponic bed show $1 \mathrm{~m}^{2}$ of cultivation area, plant density is 60 plants $/ \mathrm{m}^{2}$

over 30 or in conditions where the Relative Humidity $(\mathrm{RH})$ is lower than $70 \%$. The fogging pump will turn off when the $\mathrm{RH}$ is over $90 \%$. The fogging system was controlled by micro-controller based ON/OFF control Fig. 3.

Experimental setup: The experiments were conducted to determine the optimized R:B LED light ratio for the hydroponic 'Green-Oak' lettuce during crop for 36 days (Kim et al., 2018). The hydroponic bed was separated in four areas by using the non-transparent white plastic, each with an area of about $1 \mathrm{~m}^{2}$. The overhead LED lighting were installed above the hydroponic bed in three dark areas inside the greenhouse. The fourth cultivating area of the greenhouse was covered by the transparent $\mathrm{PVC}$, so that, this area can receive the natural Sun during 


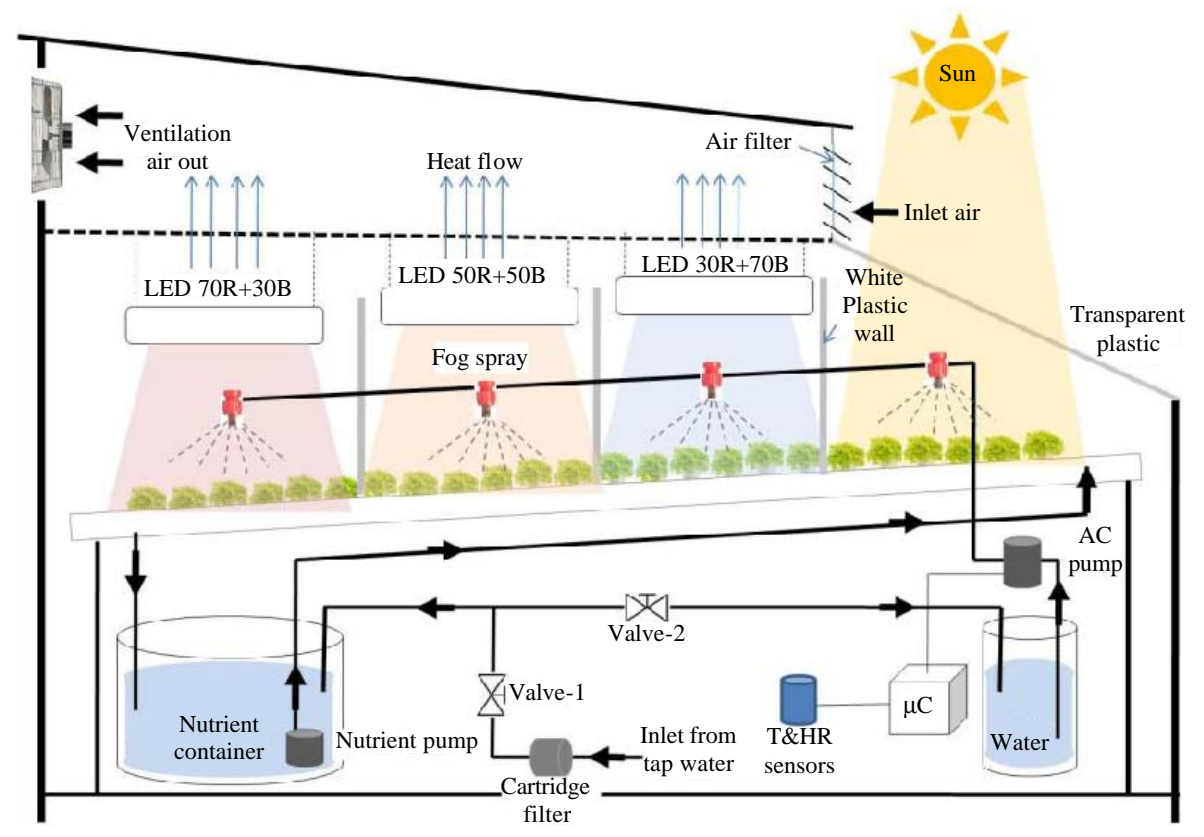

Fig. 3: Diagram of the hydroponics NFT experiment greenhouse system

the day time. The PPFD were set up, so that, each LED light source is at $300 \pm 15 \mu \mathrm{mol} / \mathrm{m}^{2} / \mathrm{sec}$. The PPFD was measured by the quantum light meter (Spectrum Technologies, Inc. USA) The LED light operates at $12 \mathrm{~h}$ photoperiod $(6.00 \mathrm{am}-6.00 \mathrm{pm})$ and is controlled by a digital timer switch.

The researcher designed the experiment to include four treatments. These treatments are: $\mathrm{Ctrl}$ treatment is the control group consisting of 60 of 'Green-Oak' lettuces (population $=60$ ). This group received treatment by the natural sunlight. $\mathrm{R} 70+\mathrm{B} 30$ treatment is the 1st experimental group receiving treatment by $\mathrm{LED}$ light at the $\mathrm{R}: \mathrm{B}$ ratio of 7:3. R50+B50 treatment is the 2nd experimental group receiving treatment by LED light at the $\mathrm{R}: \mathrm{B}$ ratio is of $5: 5$ and the $\mathrm{R} 30+\mathrm{B} 70$ treatment is the $3 \mathrm{rd}$ experimental group receiving treatment by $\mathrm{LED}$ light at the R:B ratio of 3:7. The population of each group is the same the Ctrl group Fig. 3. The sampling group is explained in the measurement section.

The 'Green Oak' lettuces were harvested at 36 days after sowing. The temperature under experiment was 35 (day/night). The relative humidity was measured by the temperature with $\mathrm{RH}$ sensor and controlled at $60-80 \%$ by the fogging spray system over the plants Fig. 3.

The experiment was conducted to determine the growth characteristic of hydroponic 'Green Oak' lettuce. The plant's height and root length were recorded every 6 days. Other plant physiological characteristics were measured at the end of the crop (day 36th). Moreover, the researcher evaluated the plant yield, the start-up cost and the energy and power consumption.
Evaluation of the hydroponics yield, start-up cost and energy consumption: The hydroponics yield is the average of the head lettuce grown under NFT hydroponics methods evaluated by the estimates of plant density, number of harvests and plant mass. The average yield of hydroponics 'Green-Oak' lettuce per year was calculated in units of $\mathrm{kg} / \mathrm{m}^{2} / \mathrm{y}$.

The start-up cost is the initial cost of the NFT hydroponic system, comprise of hydroponic system $\left(4 \mathrm{~m}^{2}\right.$ of cultivation area) included nutrient tank and pumping, greenhouse of $10 \mathrm{~m}^{2}$ area with installation, the control of temperature and relative humidity system included fogging spray and ventilation system, the LED lighting system, plant seed and nutrient solution.

The total energy consumption ( $\mathrm{kWh}$ ) is the energy used to the hydroponics production of the 'Green Oak' lettuce from the supplemental LED lighting, water pumps and cooling loads. Based on 12-h photoperiod, 1 of $30 \mathrm{~W}$ nutrient pump running for $12 \mathrm{~h} /$ day, the fogging water pump are running $4 \mathrm{~h}$ and $30 \mathrm{~min}$ daily and a $35 \mathrm{~W} 220 \mathrm{~V}$ ventilation fan was ran around $12 \mathrm{~h} /$ day. The power and energy consumption were calculated.

The energy per unit total biomass is in unit $\mathrm{kWh} / \mathrm{g}$. It is the energy consumption of the total biomass (total biomass is the biomass of the plant including the root). The $\mathrm{kWh} / \mathrm{g}$ can be calculated by the total energy consumption over the total biomass per crop, based on the plant density of 60 plants $/ \mathrm{m}^{2}$ and $3 \mathrm{~m}^{2}$ of the cultivation area. Because of we supplied the electrical 
energy for the three set of LED treatments, the power density is expressed in terms of $\mathrm{kW} / \mathrm{m}^{2}$ (Poulet et al., 2014).

Measurements: The spectral distribution and the PPFD of our LED light were measured by the spectroradiometer (Asensetek Incorporation, Taiwan).

The growth development of 'Green Oak' lettuce was investigated on the shoot system and root system. The shoot system was determined by measuring the plant height and the leaf area. The root system was determined by measuring the root length and number of roots. Lastly, the fresh weight of the 'Green-Oak' lettuce (include root) were investigated.

The plant height and root length were recorded every 6 days by selecting 12 of specific samples from each experimental group (Santos et al., 2003). The measurement protocol of the plant height was used in the same method by Fan et al. and the root length was measured by the ruler.

The number of root, leaf area and fresh weight were recorded on the 36th day (harvest day) by selecting 5 plants of specific samples from each group. The number of root was measured by using the hand counter meter to 4 digits. The leaf area was measured by using the 12 Mega pixels digital camera on the smart phone and was analyzed by the Software Image J. They were analyzed from the 1st-5th leaves (inwards) of the five plants. The fresh weight was measured by digital weight scale with the capacity of $0-200 \mathrm{~g}$ and a resolution of $\pm 0.1 \mathrm{~g}$ (Tanita, Thailand).

Statistical analysis: To compare the significant difference of root length, number of roots, plant height, leaf area and fresh weight of 'Green-Oak'. lettuce per treatment, the analysis were conducted by ANOVA $(\mathrm{p}=0.05)$. The mean separations were analyzed by Tukey post hoc test $(p=0.05)$. The IBM SPSS statistic was used for analysis. The percentage applies to explain the energy and power consumptions.

\section{RESULTS AND DISCUSSION}

\section{Growth development and yield}

The root length and the plant height: The root length of the hydroponics Green-Oak lettuce under the R70+B30 treatment was the longest with $11.583 \mathrm{~cm}$ and showed significant difference at $\mathrm{p}<0.05$ Table 1 with the other light treatments. The root length of the lettuce under R30+B70 and R50+B50 treatments has no significant difference between each other. The root length of lettuce under Ctrl
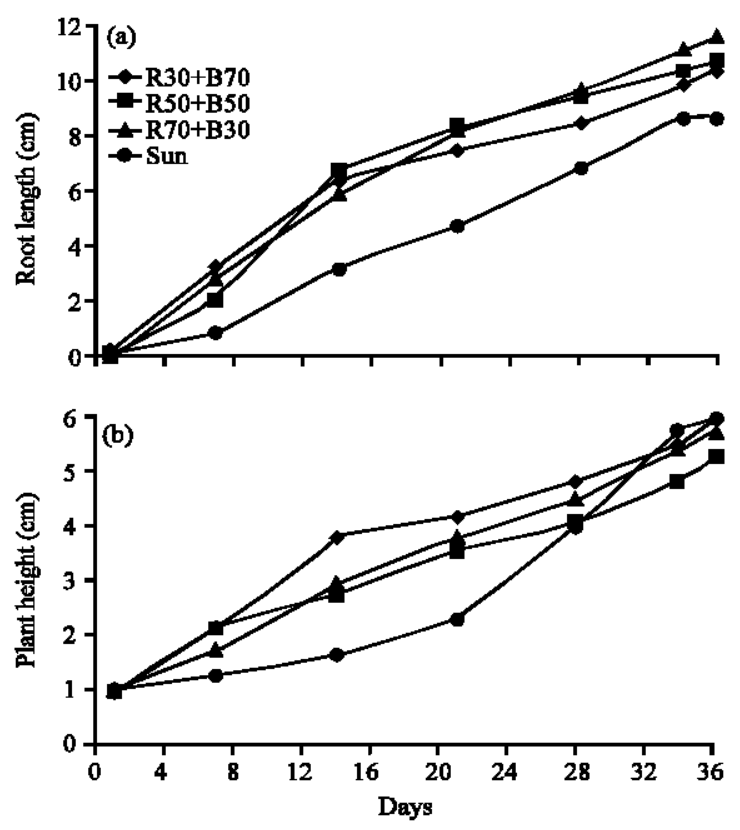

Fig. 4: Root length: a) The plant height and b) 'Green-Oak' lettuce plant over 36 days of growth

treatment was the shortest $(8.625 \mathrm{~cm})$ and indicated a significant difference at $\mathrm{p}<0.05$ from all others treatment Table 1. In the first 20 days, the root length of the hydroponics lettuce under all LED light treatment has a high increase rate from $0-8 \mathrm{~cm}$ Fig. $4 \mathrm{a}$. Subsequently, the root length increase slowly. Figure 4 shows the root length of the 'Green-Oak' lettuce under Ctrl treatment development at the slowest rate and is the shortest on the day of harvest ( 36 days).

In summary, the root length of hydroponics 'Green-Oak' lettuce under R70+B30 treatment was longer than under $\mathrm{R} 50+\mathrm{B} 50, \mathrm{R} 30+\mathrm{B} 70$ and the Ctrl treatment around 9,10 and $25 \%$, respectively.

The plant height Fig. 4b exhibit a linear increase of 'Green-Oak' lettuce growth under R30+B70, R50+B50 and R70+B30 treatment from 1st-36th days. However, the lettuce height under $\mathrm{Ctrl}$ treatment was slowly increasing from 1 st-20th days and rapidly increasing from the 21 st-36th days. The plant height was constant at the last 2 days.

In this study, the plant height of the hydroponics 'Green-Oak' lettuce was highest under Ctrl treatment $(5.916 \mathrm{~cm})$ but has no significant difference at $\mathrm{p}<0.05$ with the plant height under R30+B70 and R70+B30 treatment. Similarly, the plant height under R50+B50 was the lowest $(5.250 \mathrm{~cm})$ and showed no significant difference at $\mathrm{p}<0.05$ with the plant height under R70+B30 treatment Table 1 . The plant height under $\mathrm{R} 70+\mathrm{B} 50(\mathrm{R}: \mathrm{B}=2.33)$ is about 


\begin{tabular}{lccccc}
\multicolumn{5}{l}{ Table 1: Parameters measurement of the growth and development of hydroponics 'Green-Oak' lettuce with LED light treatment 12-h photoperiod in 36 days } \\
\hline Light treatment & Root length $(\mathrm{cm})$ & No. of roots & Plant height $(\mathrm{cm})$ & Leaf area $\left(\mathrm{cm}^{2}\right)$ & Fresh weight $(\mathrm{g})$ \\
\hline Ctrl & $8.625 \pm 1.299^{\mathrm{c}}$ & $100.400 \pm 18.433^{\mathrm{c}}$ & $5.916 \pm 0.701^{\mathrm{a}}$ & $34.509 \pm 9.915^{\mathrm{b}}$ & $21.407 \pm 4.852^{\mathrm{c}}$ \\
R30+B70 & $10.416 \pm 0.848^{\mathrm{b}}$ & $180.800 \pm 25.133^{\mathrm{b}}$ & $5.875 \pm 0.310^{\mathrm{a}}$ & $52.204 \pm 8.204^{\mathrm{b}}$ & $39.566 \pm 3.006^{\mathrm{b}}$ \\
R50+B50 & $10.541 \pm 0.541^{\mathrm{b}}$ & $161.600 \pm 18.889^{\mathrm{b}}$ & $5.250 \pm 6.657^{\mathrm{b}}$ & $48.608 \pm 7.662^{\mathrm{b}}$ & $41.762 \pm 6.425^{\mathrm{b}}$ \\
R70+B30 & $11.583 \pm 0.973^{\mathrm{a}}$ & $212.400 \pm 33.117^{\mathrm{a}}$ & $5.772 \pm 0.410^{\mathrm{a}}$ & $94.852 \pm 15.66^{\mathrm{a}}$ & $62.652 \pm 11.605^{\mathrm{a}}$ \\
\hline
\end{tabular}

${ }^{\mathrm{a}-\mathrm{c}}$ Signific ant values
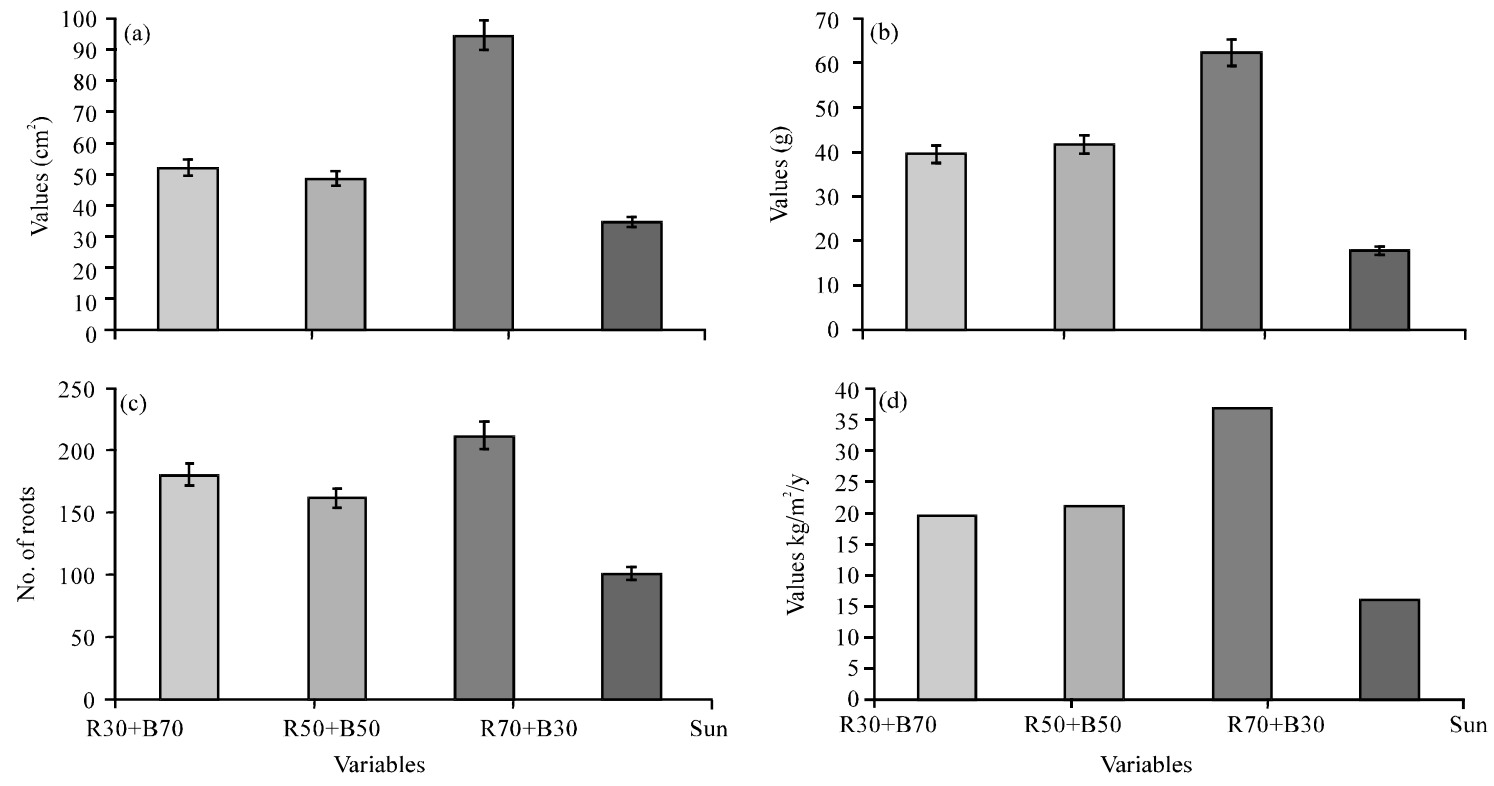

Fig. 5: a) Leaf area; b) Fresh weight; c) Number of roots of the 'Green-Oak' lettuce plant over 36 days of growth and d) Plants yield: errors bar as indicate SD

$5.773 \mathrm{~cm}$ which is lower than the plant height of the 'Green-Oak' Lettuce from the study of XL Chen (indicated as $9.10 \mathrm{~cm}$ ). This difference could be possible from two causes: firstly, the photoperiod of the LED supplement (16 $\mathrm{h}$ ) is longer than this study ( $12 \mathrm{~h}$ ) which therefore, means that the plants in the study of Chen et al. (2016) has a longer light exposure which in turn contributes to more time for photosynthesis and thus, promoting the positive of growth development of the lettuce. Secondly, the temperature inside the greenhouse from this study at day time is about 30-35 which is much higher than XL Chen study. The difference in temperature could decrease the plant height.

Leaf area, fresh weight and number of roots: Our experiment showed that the leaf area of the hydroponics 'Green-Oak' lettuce under R70+B30 treatment was the biggest $\left(94.452 \mathrm{~cm}^{2}\right)$. The statistical result shows significant difference $(\mathrm{p}<0.05)$ from all other treatments Table 1. But the leaf area of Green-Oak lettuce under $\mathrm{R} 30+\mathrm{B} 70, \mathrm{R} 50+\mathrm{B} 50$ and $\mathrm{Ctrl}$ treatment have no significant difference at $\mathrm{p}<0.05$ Table 1 and their leaf area are lower than under the R70+B30 treatment Fig. 5a. This result is in accordance with the study of Mampholo BM where the leaf area of the hydroponic 'Green-Oak' lettuce is about $1545-2289 \mathrm{~cm}^{2}$ per head. In other words, the average leaf area (per leaf) is around 91.96-136.25 $\mathrm{cm}^{2}$ (Mampholo et al., 2016) based on the average leaf number of the 'Green-Oak' lettuce from the study by Chen et al. (2016).

This study indicated that the fresh weight (including the roots) per plant of hydroponics 'Green-Oak' lettuce under R70+B30 treatment is the highest at $62.652 \mathrm{~g}$ and is significantly different $(\mathrm{p}<0.05)$ from all other treatments Table 1.

Moreover, the fresh weight of the lettuce under $\mathrm{R} 30+\mathrm{B} 70, \mathrm{R} 50+\mathrm{B} 50$ and $\mathrm{Ctrl}$ treatment were lower than the $\mathrm{R} 70+\mathrm{B} 30$ treatment with no significant difference amongst each other at $\mathrm{p}<0.05$. In summary, the fresh weight of 'Green-Oak' lettuce under R70+B30 treatment is the higher than under R50+B50, R30+B70 and Ctrl treatment by about 34,63 and $66 \%$, respectively (Fig. 5b).

Interestingly, the fresh weight per plant (62.625 g) from our study could be confirmed by the studied of T. Kleiber. They found that the fresh weight per head is about $63.5 \mathrm{~g}$ under 30 days after plants exposure to different LED light on $12 \mathrm{~h}$ of photoperiod (Kleiber et al., 2017). However, our results differ with respect to the fresh 


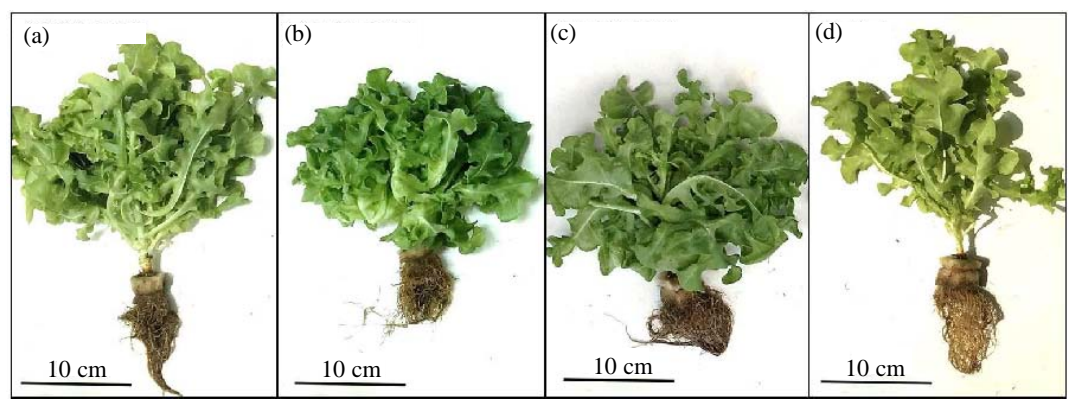

Fig. 6: The hydroponics 'Green-Oak' lettuce growth development were compared between four different lighting treatment at the harvest day (36th day): a) R30+B70; b) R50+B50; c) R70+B30 and d) Ctrl

weight of lettuce under R+B LED treatment (47.86 g/plant) at low PPFD and unknown photoperiod (Kim et al., 2018). The study of Chen et al. (2016) indicated that the fresh weight of the Green-Oak lettuce under LED light ratio of $\mathrm{R}: \mathrm{B}=2: 1$ after 30 days of crop is $87.01 \mathrm{~g} / \mathrm{plant}$. This is significantly higher than our study because the team of Chen applied the LED light for a $16 \mathrm{~h}$ photoperiod and used the temperature of $20 / 24$ which is more appropriate for plants. This reasoning is sensible to explain why the fresh weight production of the lettuce from X.L. Chen is higher than our study.

The number of roots of the hydroponics 'Green-Oak' lettuce under $\mathrm{R} 70+\mathrm{B} 30$ indicated the highest number (212.4) but showed no significant difference at $\mathrm{p}<0.05$ with 'Green-Oak' lettuce under R30+B70. Nonetheless, the number of roots under R70+B30 showed significant difference at $\mathrm{p}<0.05$ from under R50+B50 and the Ctrl treatment. The researcher the number of roots of Green-Oak lettuce under Ctrl treatment was lowest (100.4). This value is lower than under R70+B30, R30+B70 and R50+B50 by 212,180 and $161 \%$, respectively (Fig. $5 \mathrm{c}$ ). The hydroponics 'Green-Oak' lettuce growth development shows the morphological structure of the leaves, stem and root to be rather complete under all LED treatment. This morphology is shown as R30+B70 Fig. 6a, 50+B50 Fig. 6b and R70+B30 Fig. $6 \mathrm{c}$ at the harvest day ( 36 th day). The researcher observed that the 'Green-Oak' lettuce under natural Sun or the Ctrl treatment Fig. 6d lack growth development, especially in the number of roots, leaf area and fresh weight. The major cause why natural sunlight was not perfectly shone on the lettuce in the morning time is because the limitation on the location of the hydroponic experimental greenhouse and the limitation of the greenhouse structure where the wall between the $3 \mathrm{rd}$ and 4th cultivation area was shielding the sunlight. These reasons could explain about the lack of sunlight affecting to the growth and development of the hydroponic
'Green-Oak' lettuce conclusively. Figure 6 shows the comparative growth of the lettuce between different experimental groups.

Production yield: The hydroponics lettuce production yield is the average of the head lettuce grown under different LED light treatments as estimated at the plant density of 60 plants $/ \mathrm{m}^{2}$, the number of harvests per year of 10 and the plant mass (total fresh weight in one crop in $4 \mathrm{~m}^{2}$ of cultivation area) of $99.23 \mathrm{~kg} / \mathrm{y}$. The specific yield of the hydroponics 'Green-Oak' lettuce per year under $\mathrm{R} 30+\mathrm{B} 70$ treatment was projected at $23.74 \mathrm{~kg} / \mathrm{m}^{2} / \mathrm{y}$, under $\mathrm{R} 50+\mathrm{B} 50$ at $25.06 \mathrm{~kg} / \mathrm{m}^{2} / \mathrm{y}$, under R $70+\mathrm{B} 30$ at $37.59 \mathrm{~kg} / \mathrm{m}^{2} / \mathrm{y}$ (making this treatment the highest yield) and under natural Sun at $12.84 \mathrm{~kg} / \mathrm{m}^{2} / \mathrm{y}$ (giving the lowest yield) (Fig. 5d). The average of the production yield of this study is about $24.81 \mathrm{~kg} / \mathrm{m}^{2} / \mathrm{y}$. The total average production yield was low because of the lack of sunlight on the 4th cultivation which consequently decreased the total production yield. The production yield of the 'Green-Oak' lettuce under LED R70+B30 treatment was shown to be $37.59 \mathrm{~kg} / \mathrm{m}^{2} / \mathrm{y}$. This value is very close to the hydroponics production lettuce in Arizona with the yield of about $41 \pm 6.1 \mathrm{~kg} / \mathrm{m}^{2} / \mathrm{y}$ based on plant density 42 plants $/ \mathrm{m}^{2}$. This mean that if we produce the lettuce under the LED supplement of $\mathrm{R}: \mathrm{B}=7: 3$ and increase the photoperiod to $16 \mathrm{~h}$, an increase in the production yield to at least $150 \mathrm{~kg} / \mathrm{y}\left(37.59 \mathrm{~kg} / \mathrm{m}^{2} / \mathrm{y} \times 4 \mathrm{~m}^{2}\right)$ will be very likely. However, additional factors will also have to be taken into account for becausethe temperature in average is 25 and the relative humidity is between $60-80 \%$.

\footnotetext{
Evaluate the start-up cost and electrical energy consumption

Start-up cost: The start-up cost was evaluated based on the equipment of this project consisting of five major parts. The hydroponic system (including the nutrient tank and water pump) costs about $11,000 \mathrm{THB}$ or $20 \%$ of total cost.
} 
(a)

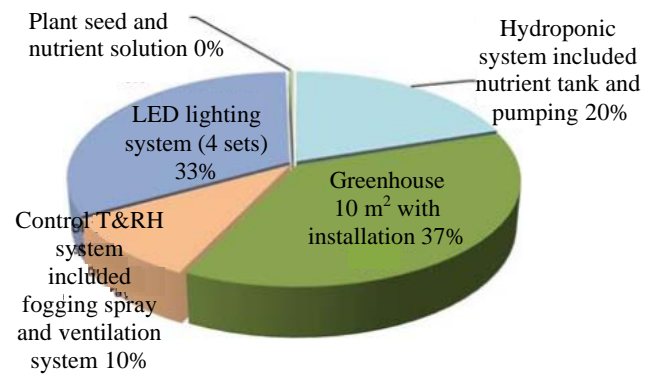

(b)

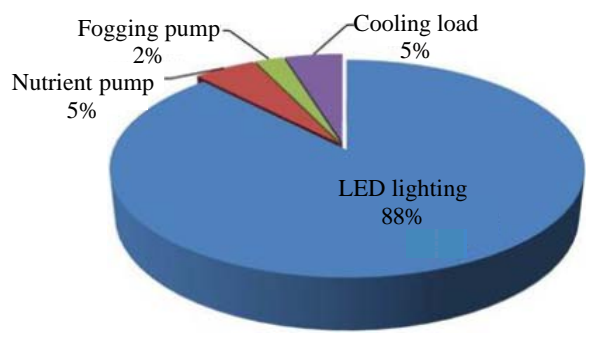

Fig. 7: a) Start-up cost and b) an electrical energy consumption of the hydroponics production of the 'Green-Oak' lettuce

The $10 \mathrm{~m}^{2}$ green house $(2.2 \times 5 \times 3 \mathrm{~m})$ with the iron structure and is covered by UV resistant plastic costs $20,500 \mathrm{THB}$ (including installation) or $37 \%$ of the total. The control of temperature and relative humidity including the four head fogging sprays and a ventilation fan costs $5,400 \mathrm{THB}$ or $10 \%$ of the total costs. The LED lighting system costs about $18,000 \mathrm{THB}$ or $33 \%$ of total costs. The researcher estimated this cost for 4 set of LED arrays due to the fact that the greenhouse have $4 \mathrm{~m}^{2}$ of hydroponic bed $\left(1 \mathrm{~m}^{2} / 1\right.$ LED set). Lastly, the plant seed and nutrient solution. The initial cost for this final part is very low which is $<1 \%$ of the total start-up cost (Fig. 7a). The greenhouse cost is around $37 \%$ of the total cost and is the highest cost of the whole experiment. In fact, for the indoor cultivating, we need the hydroponic system and the LED lighting system and thus, there is no real need for the greenhouse. Therefore, this that application of the LED growth lighting system for indoor plants cultivation could save start-up costs. From this study, the researcher could estimate the start-up cost for hydroponic indoor cultivation including LED lighting system to be around 29,000 THB (878 USD) for $4 \mathrm{~m}^{2}$ of growing area. However, the cost of LED lighting is necessary for promoting the lettuce yield for greenhouse with the lack of sunlight and for indoor cultivation and the plant factory.

Electrical energy consumption: The measured and calculated total energy consumption $(\mathrm{kWh})$ of the hydroponics production of the 'Green-Oak' lettuce is equal to $324.21 \mathrm{kWh} / \mathrm{crop}$. Most of the energy consumption is from the LED lighting system (calculated by measuring the DC current and voltage) which made up about $88 \%(285.12 \mathrm{kWh})$ of the total energy consumption. The energy supplied for the nutrient pump is about 5\% (16.41 kWh) for fogging pump is $2 \%(7.56 \mathrm{kWh})$ and the cooling loads is around $5 \%(15.12 \mathrm{kWh})$ as show in Fig. 7b. Energy per unit total biomass (Poulet et al., 2014) was evaluated in unit $\mathrm{kWh} / \mathrm{g}$. The total plant fresh weight in one crop (based on $3 \mathrm{~m}^{2}$ of cultivation area under LED treatment) is about
$8638.8 \mathrm{~g}$ ( 60 plants per crop $\times$ Fresh weight per plants from all LED treatments). The evaluated result of the energy per unit total biomass of 'Green-Oak' lettuce in this study is equal to $0.038 \mathrm{kWh} / \mathrm{g}$.

Lastly, the power density $\left(\mathrm{kW} / \mathrm{m}^{2}\right)$ from the proposed LED lighting system on average is equal to $0.22 \mathrm{~kW} / \mathrm{m}^{2}$. This result is in accordance with the study of L. Poulet because our result is not too far from the power density of the targeted LED R+B $\left(0.08 \mathrm{~kW} / \mathrm{m}^{2}\right)$ and very similar to the LED coverage $\mathrm{R}+\mathrm{B}\left(0.202 \mathrm{~kW} / \mathrm{m}^{2}\right)$ (Poulet et al., 2014). In addition to that, this study indicated that the LED lighting for lettuce growth significantly save energy better than the classical light sources for the previous studies such as the HID lighting system for plants growth with the power density of $2.47 \mathrm{~kW} / \mathrm{m}^{2}$ (Hubits et al., 2004) and the HPS lighting for the NASA Biomass Production Center with the power density of $2.1 \mathrm{~kW} / \mathrm{m}^{2}$ (Wheeler et al., 1996).

For the plant factory and indoor cultivation system, the LED light source is essential equipment that consumed a big amount of energy. This study showed that around $88 \%$ of total electrical energy was consumed for the LED system. The ways to reduce the energy consumption is to reduce the power of LED light by not reducing the PPFD. The researcher would like to propose the next study to apply the low power (strip type) LED light source over the hydroponic bed. This is because the strip LED will consume less energy and is able to produce low quantum flux. This will be essential in order to optimize the distance of the light source over the plant which could produce the PPFD between 200-250 $\mu \mathrm{mol}$ $\mathrm{m}^{-2} / \mathrm{sec}$ by combining the red and blue LED photon flux ratio of about 70:30.

\section{CONCLUSION}

Hydroponic 'Green Oak' lettuce under LED R70+B30 indicated the highest physical, response in root length, number of root, leaf area and fresh weight then could 
produce the highest yield. The star-up costs of the HS include LED light (HS-LED) is around $7,250 \mathrm{THB} / \mathrm{m}^{2}(220$ $\mathrm{USD} / \mathrm{m}^{2}$ ). The energy per unit total biomass of hydroponic 'Green-Oak' lettuce is equal to $0.038 \mathrm{kWh} / \mathrm{g}$ and the power density of the proposed LED lighting in average is 0.22 $\mathrm{kW} / \mathrm{m}^{2}$. It is possible to apply LED lighting for hydroponic indoor greenhouse in high plants density which could produce high yield and a good quality of the lettuce.

The LED lighting system consumed the biggest number of energy for the energy sustainability, the LED needs to be change to the low power consumption types (strip type) and apply the new design for the LED light source. The results from this study could apply to be a design for the effective of HS-LED in the next step.

\section{ACKNOWLEDGEMENT}

The researchers wished to show gratitude for the research budgets from the National Research Council of Thailand in year 2017.

\section{REFERENCES}

Anonymous, 2017. Global report on food crises. World Food Programme, Rome, Italy.

Anonymous, 2019. Current world population. Worldometers Inc., USA. http://www. worldometers. info/world-population/\# table-forecast

Attanandana, T. and S. Watcharothayan, 1988. Hydroponics. Thai J. Soil Fertilizers, 10: 59-66.

Chen, X.L., X.Z. Xue, W.Z. Guo, L.C. Wang and X.J. Qiao, 2016. Growth and nutritional properties of lettuce affected by mixed irradiation of white and supplemental light provided by light-emitting diode. Sci. Hortic., 200: 111-118.

Donnell, M., T. Short, R. Moore and C. Draper, 2011. Hydroponic greenhouse lettuce enterprise budget. Msc Thesis, Ohio State University, Columbus, Ohio.

Hublitz, I., D.L. Henninger, B.G. Drake and P. Eckart, 2004. Engineering concepts for inflatable Mars surface greenhouses. Adv. Space Res., 34: 1546-1551.

Juthamas, P. and W. Boonsongsri, 1988. Soilless culture. Thai J. Soil Fertilizers, 10: 92-96.
Kim, B., D. Lee and K. Chun, 2018. Eco-friendly LED plant factory development. J. Eng. Appl. Sci., 13: 541-545.

Kleiber, T., K. Borowiak, A. Schroeter-Zakrzewska, A. Budka and S. Osiecki, 2017. Effect of ozone treatment and light colour on photosynthesis and yield of lettuce. Sci. Hortic., 217: 130-136.

Koohakan, P., T. Jeanaksorn and I. Nuntagij, 2008. Major diseases of lettuce grown by commercial nutrient film technique in Thailand. Curr. Appl. Sci. Technol., 8: 56-63.

Mampholo, B.M., M.M. Maboko, P. Soundy and D. Sivakumar, 2016. Phytochemicals and overall quality of leafy lettuce (Lactuca sativa L.) varieties grown in closed hydroponic system. J. Food Qual., 39: 805-815.

Matsumoto, N., 2002. Development of Sustainable Agricultural System in Northeast Thailand Through Local Resource Utilization and Technology Improvement. Japan International Research Center for Agricultural Sciences, Tsukuba, Japan, Pages: 237.

Montri, N. and E. Wattanapreechanon, 2006. Soilless culture in Thailand. Proceedings of the 27th International Congress on Horticultural (IHC2006), August 13-19, 2006, COEX Convention Center, Seoul, Korea, pp: 187-193.

Poulet, L., G.D. Massa, R.C. Morrow, C.M. Bourget and R.M. Wheeler et al., 2014. Significant reduction in energy for plant-growth lighting in space using targeted LED lighting and spectral manipulation. Life Sci. Space Res., 2: 43-53.

Santos, A.M.P., G.B. Fernandes, M.D.G.A. Korn, R.P. Dantas and S.L.C. Ferreira, 2003. Mineral composition of lettuce (Lactuca sativa L.) grown in soil and hydroponics consumed in salvador city, Brazil. J. Food Technol., 1: 42-45.

Wheeler, R.M., C.L. Mackowiak, G.W. Stutte, J.C. Sager and N.C. Yorio et al., 1996. NASAs biomass production chamber: A testbed for bioregenerative life support studies. Adv. Space Res., 18: 215-224. 